\title{
A crise não é do jornalismo, mas do seu financiamento: entrevista com Jean Charron
}

\author{
Lívia Guilhermano \\ Mestranda; Universidade Federal do Rio Grande do Sul, Porto Alegre, RS, Brasil \\ liviaguilhermano@gmail.com
}

\section{Resumo}

Nesta entrevista, o pesquisador Jean Charron, da Universidade Laval, no Canadá, argumenta que o paradigma dominante no jornalismo contemporâneo ainda é o "de comunicação", cuja vigência teria se iniciado nos anos 1970 e 1980. O modelo, descrito por ele e Jean de Bonville em 2004, caracterizase pela multiplicação de suportes, pela hiperconcorrência, pela superabundância de oferta de informações e ênfase na função fática do discurso. Para chegar ao conceito de "jornalismo de comunicação", os autores utilizaram o método weberiano de construção de tipos ideais para contar a história do jornalismo norte-americano a partir do século XVII. Por fim, o autor sustenta que hoje a crise não é do jornalismo, mas do financiamento da sua produção.

\section{Palavras-chave}

Jornalismo. Jornalismo de Comunicação. Jean Charron.

Jean Charron é professor titular do Departamento de Informação e Comunicação da Universidade Laval, localizada na Cidade de Quebec, capital da província do Quebec, no Canadá. Com títulos de mestrado e doutorado em Ciências Políticas pela própria Laval, realizou pós-doutorado na Universidade de Bordeaux, na França. Juntamente com o historiador Jean de Bonville, criou em 1992 o Grupo de Pesquisa sobre as Mutações do Jornalismo (Groupe de Recherche sur les Mutations du Journalisme, GRMJ). Como resultado das pesquisas do grupo, lançou, em 2004, pela editora Les Presses de L'Université Laval, o livro Nature et transformation du journalisme. Théorie et recherches empiriques, em coautoria com de Bonville. 
Foram alunos e professores da Universidade de Brasília (UnB), liderados pela professora Zélia Leal Adghirni, os primeiros a trabalhar com a pesquisa dos autores canadenses no Brasil. A versão brasileira, Natureza e transformação do jornalismo, foi publicada em 2016 pela Editora Insular e, em 2018, passou a fazer parte da bibliografia obrigatória da linha de pesquisa Jornalismo e Processos Editoriais no processo de seleção do Programa de Pós-Graduação em Comunicação e Informação da Universidade Federal do Rio Grande do Sul (PPGCOM/UFRGS). Na obra, Jean Charron e Jean de Bonville (2004; 2016) analisam as mudanças no jornalismo ao longo do tempo a partir de referencial teóricometodológico weberiano. Para os autores (2004; 2016), a história do jornalismo pode ser periodizada em quatro tipos ideais, que funcionam como paradigmas (modelos predominantes): jornalismo de transmissão (século XVII); jornalismo de opinião (século XIX); jornalismo de informação (final do século XIX e início do século XX); jornalismo de comunicação (a partir das décadas de 1970 e 1980). Este último paradigma identificado pelos autores $(2004 ; 2016)$ seria caracterizado pela multiplicação de suportes midiáticos e dos serviços de informação em um cenário de hiperconcorrência. Nesse período, o comentário, o humor e a informalidade seriam aceitos no discurso jornalístico, a informação se aproximaria do entretenimento e o jornalista assumiria um tom de familiaridade com a audiência.

Essas caracterizações, assim como a metodologia utilizada pelos autores, foram tema de intensos debates no primeiro semestre de 2017 no PPGCOM/UFRGS, no âmbito do Laboratório de Pesquisa coordenado pela professora Dra. Virginia Fonseca, do qual faço parte. Entre outras questões, passamos a nos perguntar se, com o impacto da internet e das mídias sociais na produção da notícia, estaríamos vivenciando um novo período de mutação no jornalismo, ou seja, se estaríamos no limiar de um novo paradigma. No segundo semestre, tive a oportunidade de ir ao Quebec, no Canadá, e graças à mediação dos professores François Démers (Laval), Fábio Henrique Pereira (UnB) e Zélia Leal Adghirni, pude conversar pessoalmente com Jean Charron na Universidade Laval. Foi em novembro de 2017 que o professor me recebeu em seu pequeno gabinete no prédio histórico construído nos anos 1940 para ser um seminário da Igreja Católica, e gentilmente concedeume a seguinte entrevista. 
Na obra Natureza e Transformação do Jornalismo, Jean de Bonville e você dividem a história do jornalismo em quatro períodos, sendo o último o do jornalismo de comunicação. Você acredita haver um novo paradigma em desenvolvimento que possa superá-lo? Por quê?

Eu trabalhei por muitos anos com os historiadores. Eu não sou historiador, mas trabalhei muito com eles. E quando o assunto é alguma coisa que se passa na atualidade, eles têm a tendência a recuar. Eles falam: "eu não sei". Eles costumam olhar para 20, 30, 40 anos atrás. Falar de hoje não é a área deles. São os jornalistas que fazem isso, que são os observadores, assim como os sociólogos e os cientistas políticos. Os historiadores não falam do período contemporâneo. Antigamente, eu não tinha esse hábito. Quando trabalhei com eles, eu era aquele que deveria ser o mais interessado no período contemporâneo. Mas eu penso que adquiri o modo de pensar deles ao longo dos anos, que faz com que eu não ouse muito especular o que está em curso e o que vai acontecer em 20 ou mesmo em cinco anos. Ainda teremos jornais em alguns anos? Eu não sei. Como as pessoas vão se informar? Eu não sei. As pessoas da nova geração não se informam como as pessoas da minha geração e, então, nos damos conta de que as diferenças são muito marcantes. Nós estamos hoje em um contexto de grande incerteza. 0 conjunto do sistema funciona com uma grande incerteza. Os gestores da mídia, os jornalistas, os editores... Eles têm muita dificuldade de projetar o futuro. Eles navegam às cegas. De Bonville e eu desenvolvemos conceitos que se inscrevem em uma longa duração, como o de paradigma, por exemplo. Para nós, o conceito de paradigma não é uma coisa que muda do dia para a noite. São estudos sociais muito profundos, que evoluem muito lentamente. E quando a gente chega a dizer que há uma mudança de paradigma é porque uma soma de mudanças, de evoluções ao longo do tempo, faz com que em um dado momento nós percebamos que não estamos mais no mesmo universo de outrora. Mas atualmente nós não chegamos a observar isso, porque não sabemos em qual universo nos situamos. Não sabemos em qual universo vamos estar amanhã ou depois de amanhã. Então, a especulação, a projeção, se torna difícil. Mas ao mesmo tempo, como os conceitos que nós desenvolvemos foram concebidos em uma perspectiva de longo prazo, o que eu percebo das mudanças atualmente é que elas parecem confirmar evoluções que nós percebemos há 20 ou 30 anos. Do ponto de vista do paradigma jornalístico, eu não vejo, neste momento, revolução. Eu vejo muitas mudanças. Mas 
mudanças que não tiveram o tempo de se sedimentar, de se solidificar no fundo do rio. Ainda está nebuloso. Não sabemos se vai se estabelecer finalmente ou qual mudança que se produziu. Estamos ainda no turbilhão. Então, por um lado, eu hesito especular. Eu vejo as evoluções, naquilo que nós chamamos de paradigma jornalístico, no sentido de que o suporte material muda muito. Mas a concepção que está por trás disso é diferente hoje do que era há 20 anos? Eu acredito que não. Por exemplo, a ideia do jornalismo de comunicação é um jornalismo que acentua a função fática, a função do contato. Eu sou um jornalista, eu lhe trago as notícias, mas eu falo com você. Eu não descrevo simplesmente o mundo. Eu tento virtualmente ou simbolicamente estabelecer contato. Quando a gente olha a maneira de trabalho de jornalistas on-line, nós vemos bem esses traços de interação. No entanto, essa preocupação aparece no final dos anos 1960 em um contexto aqui do Canadá. Esses traços aparecem e se firmam ao longo do tempo. Então não é uma coisa fundamentalmente diferente. Por exemplo, quando um jornalista envia uma mensagem no Twitter, já não é a mesma coisa que em uma página de um jornal ou uma matéria na televisão. A via é direta. 0 Twitter permite interações assim. Aqui no Quebec, no Canadá, no começo, todo jornalista tinha conta no Twitter - se transformou em uma espécie de moda. Mas, depois disso, houve um retorno e os jornalistas tuítam cada vez menos. Isso não é o nosso trabalho. Nós voltamos a essa dimensão que nós chamamos de jornalismo de comunicação e ele não está verdadeiramente exacerbado pelas novas possibilidades técnicas. 0 que nos freia é justamente a identidade profissional, que é estrutural. Ela não muda assim tão rápido. A gente pode tentar inovar com todos os tipos de tecnologias, mas a gente percebe que os jornalistas têm a tendência de utilizá-las em função desta identidade profissional e desses valores profissionais e não modular os valores em função da tecnologia. Eles se apropriam da tecnologia em função dos valores, porque a tecnologia muda rapidamente, mas os valores, as concepções profissionais, não mudam tão rapidamente assim. Há uma espécie de dialética entre o que chamamos de estrutura, que eu associo ao paradigma, e os efeitos de conjuntura, que são ligados às novas tecnologias ou tentativas de fazer isso ou aquilo para se ajustar à mudança. Aqui temos elementos de conjuntura, mas eles fazem a estrutura evoluir mais devagar. 


\section{Então, você acredita que as características do jornalismo de comunicação permanecem?}

Sim. Eu as vejo cotidianamente. Eu as vejo no meu jornal tradicional de papel. Eu as vejo todos os dias nas notícias tradicionais. E quando eu vou consultar as mídias on-line, eu vejo a mesma coisa. Nesse aspecto, não me parece que há muita diferença. Entretanto, as mídias on-line oferecem hiperlinks, vídeos... Podemos ter acesso a muitas coisas. Mas qual é a relação que se estabelece entre o jornalismo de comunicação e o jornalismo que me explica alguma coisa? É essa relação que eu observo atualmente no papel ou no on-line e é ela que estava em elaboração há 30 anos ou há 40 anos. Por isso, então, eu não vejo revolução.

\section{Você acredita que as mudanças que vemos atualmente se limitam a questões técnicas ou você vê outras mudanças, como no papel do jornalista, por exemplo?}

As mudanças técnicas são evidentes. Isso tem repercussão econômica. Quando eu falo de um contexto de incertezas, são incertezas sobretudo econômicas, ou seja, como produzir atualmente informação e rentabilizar a operação. Não sabemos mais como fazer isso. Nós sabíamos como fazer há 150 anos, 200 anos. Nós procurávamos verbas publicitárias e assinaturas das revistas e funcionávamos assim. Hoje nem as assinaturas nem as verbas publicitárias parecem funcionar. Então, como se deve proceder? As mudanças são causadas por inovações técnicas, sobretudo no universo digital que revolucionou tudo. Mas a minha hipótese é que as representações profissionais, os valores profissionais, são mais estáveis que isso. A prática também muda para o público, por exemplo. Mas o público não muda tão rápido também. As pessoas procuram todos os dias informações sobre a atualidade, ler as notícias, ter compreensão sobre os acontecimentos. Eu insisto em pensar que o fator mais suscetível de fazer mudar a prática jornalística é o fator econômico. Não é a tecnologia. É indiretamente a tecnologia. Mas a tecnologia faz com que os modos de fazer o que a gente fazia anteriormente, que funcionavam, não funcionem mais. Não conseguimos mais rentabilizar um jornal. Então como nós fazemos para produzir a informação? Nós podemos criar dispositivos, como nós fazemos com as mídias digitais, que fazem circular a 
informação. Nós podemos produzir e coletar informações factuais, colocá-las em ordem, organizá-las e dar um sentido para elas. Mas para isso é preciso ter recursos humanos e, antes de mais nada, é preciso ter financiamento. E é isso que está em crise. Jornalistas e gestores procuram novas maneiras de fazer aquilo que faziam anteriormente e não maneiras de tentar fazer outra coisa, porque eles pensam que é isso que precisa ser feito. É preciso produzir informações de interesse público. É preciso interessar ao público. É preciso informar sobre as eleições, etc. Isso não muda assim rapidamente. Então, hoje as pessoas vão dizer: "é preciso estar atento ao público, ele não nos escuta mais, não nos lê mais...". Isso não é verdade. 0 público ainda nos lê e nos escuta. Mas é preciso interessar ao público. Nos anos 1940, nos anos 1950, no pós-guerra, nós não dizíamos isso. Não era o que vai interessar ao público, mas o que era importante para o público. No jornalismo de comunicação, a gente pensa "o que o meu público vai entender? Como ele percebe as coisas?", para, então, podermos nos ajustar a essa percepção. Isso aparece no discurso dos anos 1970 e 1980. E hoje é a mesma coisa. Eu não percebi uma mudança nesse discurso.

\section{Então, você não acredita na crise do jornalismo?}

Para mim, a crise do jornalismo é a crise do financiamento da produção da informação. A crise não é de um desinteresse do público pela informação. É verdade que os jovens se interessam menos pelas atividades públicas. Sem dúvida há um problema de educação. Há relações com as instituições que mudam. Mas o comportamento em geral do público, mesmo se é prático, concreto, de leitura, nós podemos mudar: ler no tablet ao invés de ler no papel... Mas o leitor procura fundamentalmente a mesma coisa. Então não é uma crise do público. Não é uma crise do jornalismo ou no sentido de os jornalistas não saberem mais como fazer o seu trabalho. Eles sabem como fazer. Financiar é que eles não sabem como. Então, falta a eles mudar o modo de organização, criar empresas sem fins lucrativos, ter recursos de patrocínios públicos ou patrocínios privados, no lugar do financiamento publicitário. Nós procuramos novos meios, mas é para fazer aquilo que nós queremos fazer, aquilo que nós pensamos que tem que ser feito, ou seja, para responder às exigências do paradigma dominante, do paradigma do jornalismo de comunicação. Então, a crise do jornalismo é uma crise real no sentido de que o jornalismo é uma instituição e que não sabemos mais como fazê-la funcionar, como financiá-la. Isso provoca uma situação de crise. 
Mas não é o antijornalismo. Não é que não sabemos fazer o jornalismo. Nós sabemos como fazer e o público ainda quer. A pergunta é como organizá-lo para que seja viável financeiramente.

\section{É por isso que você afirma vivermos um período de incerteza? Não vemos à nossa frente possíveis soluções?}

É preciso criar soluções que permitam que o trabalho de produção da informação seja feito. Não é uma nova concepção de produção da informação, mas é ter uma nova maneira de rentabilizar essas operações. Como conseguir recursos para fazê-las? Eu acredito que é essa questão que os jornalistas se colocam. Talvez alguns se coloquem a questão: “como reinventar o jornalismo?". Mas eu não penso que esse seja o ponto de vista dominante. Nós continuamos pensando que precisamos cobrir a política, o esporte, as artes, a cultura, que é preciso compreender o universo em que nós vivemos, informar as pessoas cotidianamente. Acontecimentos seguem sendo acontecimentos. Isso tudo fundamentalmente não mudou. Mas onde conseguir os recursos para fazer? Há alguns anos, aqui no Quebec, houve um conflito, uma manifestação. Jornalistas bloquearam a entrada do seu local de trabalho. Quando o bloqueio terminou, um terço deles voltou a trabalhar e os outros foram demitidos. Imagina no cotidiano de um jornal a demissão de dois terços da equipe. A partir daquele momento não tem mais como funcionar, certo?

Nós escrevemos para um jornal que se chama L'Huffington Post. É um jornal on-line. Não tem quase nenhum jornalista que trabalha lá. Tem editor, editor-chefe, um jornalista no parlamento, e um ou dois freelancers. Quando tivemos o bloqueio, o jornal seguiu sendo publicado durante um ano, mesmo com todos os jornalistas na rua. Isso significa que podemos fazer um jornal funcionar com tecnologias, mas sem jornalistas. Mas isso não está certo, isso não é um jornal. Esse não é o futuro do jornalismo. Não é jornalismo. É outra coisa. E os jovens iniciantes no jornalismo pensam basicamente da mesma maneira que os mais velhos. Então, para voltar à questão anterior, eu não percebo em todos esses movimentos uma mudança paradigmática. Eu penso, em vez disso, que é o jornalismo de comunicação que continua a se desenvolver, mas através de uma crise que se coloca. Quanto à mudança de paradigma, nós desenvolvemos uma ideia de que, em uma escala histórica, 
quando há momentos de tensão que se repetem, há uma crise paradigmática. Mas essa crise paradigmática é uma coisa de longa duração. É quando nós olhamos as coisas do passado que podemos dizer: lá teve uma fase de crise. Nos anos 1970 e 1980, quando nós anunciávamos o jornalismo de comunicação, ninguém dizia que havia uma crise. No entanto, no período contemporâneo, a fase é vivida pelos agentes como uma crise. Eles falam: "existe uma crise do jornalismo". Então eu respondo que, no meu vocabulário, nos meus conceitos teóricos, não é uma crise. Mas na vida vivida, na perspectiva subjetiva dos atores hoje, dos jornalistas, existe uma crise. "A gente está se manifestando. Eles nos demitem e mesmo assim os jornais funcionam. Tem algum problema aqui." Eles percebem isso como uma crise. Mas não é uma crise paradigmática. É uma crise de financiamento que perturba a organização da mídia, a instituição, etc. Talvez em 20 anos se vá dizer: "Sim. Tinha uma mudança. Nós não vimos, mas estava lá". Quando nós diagnosticamos cada época, o jornalismo de opinião que se transformou em jornalismo de informação, por exemplo, nós percebemos bem a posteriori. Nós olhamos após um longo período. É a mesma coisa com o jornalismo de comunicação. Nós percebemos porque nós vimos a evolução sobre 30 ou 40 anos. Hoje em dia, as mudanças são tão rápidas que talvez esteja havendo uma mudança paradigmática escondida que nós não percebemos e que nós veremos futuramente.

\section{Aqui na Universidade Laval existem grupos de pesquisa que seguem trabalhando com o paradigma jornalístico?}

Sim. Nós continuamos trabalhando com o paradigma jornalístico. Eu, nos últimos anos, juntamente com meus alunos, tenho trabalhado com a televisão. No contexto de Quebec, há poucos trabalhos de pesquisa sobre a televisão. Então, nós documentamos. Antes, eu me interessei pela evolução da imprensa escrita, no pós-guerra até os anos 2000, para mostrar as transformações paradigmáticas. Mas nós podemos fazer o mesmo com a televisão. Então eu comecei esse trabalho com colegas e estudantes. Passei a trabalhar com a evolução do telejornal a partir dos anos 1960. Os arquivos televisivos aqui são muito fragmentados, mas nós reunimos um corpus para ver a evolução da maneira de fazer os noticiários a partir dos anos 1960, 1970, 1980 até os anos 2000, para documentar a passagem do jornalismo de informação para o jornalismo de comunicação, através dos boletins de notícias. 


\section{E é diferente com a televisão?}

Sim e não. É diferente porque, como é uma mídia diferente, as formas são diferentes. As marcas, os traços que nós procuramos não são da mesma natureza, apesar de designarem os mesmos conceitos. É a mesma ideia de observar um jornalismo que é referencial - o jornalismo de informação - até um jornalismo que dá cada vez mais importância à função fática - que é o jornalismo de comunicação. Para ver um exemplo, de maneira um pouco engraçada, quando nós olhamos os boletins de notícias nos arquivos a partir dos anos 1960, nós vemos um apresentador de notícias que se dirige à tela, que olha para as pessoas, que cumprimenta para a câmera e começa a ler no papel. Depois levanta a cabeça e continua a ler. Nos anos 1970, ele continua a ler, mas a sua cabeça levanta constantemente, como se não quisesse perder o seu olhar. A partir dos anos 1980, há o teleprompter. Ele fala para a câmera e não está mais lendo. Se olharmos para isso em versão acelerada seria assim: em 1960, tinha a cabeça abaixada, nos anos 1970 ele ficava levantando e baixando a cabeça e em um determinado momento ele olha constantemente. Depois, um pouco mais tarde, ele não só está lendo, mas adota um tom de conversa e vai ter características de um animador. Esse contexto fático aparece mesmo sem som, só com a imagem nós vemos na hora essa atitude. Tem muitos discursos e marcas que mostram que o jornalismo assume cada vez mais essa subjetividade e a característica do sujeito. Eu falo com você. Eu compreendo. Eu te explico o que eu compreendi. Cada vez mais interpretativo, mais analítico, mais de dar referências ao público, referências dos acontecimentos passados conhecidos. 0 registro é menos formal, mais coloquial, mais em tom de conversa. Percebemos todas essas mudanças, essas marcas, que não são da mesma natureza que as que nós encontramos no contexto escrito, mas que vão ter o mesmo sentido que aquelas que a gente vê na escrita, de um jornalismo cada vez mais subjetivo, que fala diretamente com as pessoas, como duas pessoas que se falam. Mas faltava documentar. Esse exercício não tinha sido feito. Além disso, nós fazemos também um trabalho sobre a programação. Nós classificamos as exibições gerais de informação e nós vemos como evolui na programação. Então, nós continuamos a trabalhar com esse conceito de paradigma, mas em relação à televisão. Também, nos últimos anos, começamos a refletir sobre um conceito que nós evocamos um pouco rapidamente no livro Natureza e transformação do jornalismo, mas sobre o qual nós quisemos refletir um pouco mais, que é o conceito de contrato de comunicação. É um conceito que os analistas do discurso utilizam, relativamente simples, que consiste em dizer 
que quando nós estamos em uma situação de comunicação, como, por exemplo, nesta entrevista, existe um contrato. Eu falo e, enquanto eu não paro de falar, você não fala. Você me escuta. É o que está previsto no contrato. Se fosse o inverso, não funcionaria, seria você que falaria, eu escutaria, eu faria as perguntas, mas teria algo errado. Nós dois temos um contrato. Então, nós queríamos aplicar esse conceito na perspectiva de mudança paradigmática, observando que entre o público, as mídias e os jornalistas existe um contrato. Na verdade, existe uma sobreposição de contratos. Eu sou jornalista e eu sou público, e quando eu me informo existe um contrato que é estabelecido. Um jornalista, não importa o que fale, se dirige ao público de uma certa forma. E eu, enquanto público, escuto. Se for um jornalismo relacionado à política, é uma coisa. Se for jornalismo esportivo, será diferente. Os atores vão ser diferentes, porque nós não tratamos do esporte da mesma forma que da política. Mas é como se tivesse um subcontrato. Se eu falo de esporte ou de política em um discurso de notícias, de informação, não é a mesma coisa que um artigo de opinião, ou de um editorial. As regras são diferentes. Então, nós tentamos refletir sobre essa ideia. Há conjuntos de regras de aplicação geral e de regras de aplicação mais específica. Quando nós estamos em uma situação de comunicação, como um jornalista que escreve um texto em um jornal, há regras que são ativadas nesse sentido. E a mudança paradigmática consiste em dizer que as cláusulas do contrato se transformam. Há cláusulas mais específicas que podem se transformar rapidamente sem colocar em causa as regras mais gerais. Mas em algum momento, de tanto mudar as regras mais específicas, nós vemos mudar as regras mais gerais. De tanto fazer pequenas operações de transformação, chega um momento que a concepção geral acaba sendo modificada. Então nós realizamos um trabalho sobre esse assunto. Os estudantes que fazem a tese em comunicação ou em jornalismo trabalham todos sobre a situação de comunicação, obviamente. As pessoas que trabalham com o jornalismo sabem que ele se transforma. Mas essa problemática da transformação é uma ideia do pesquisador que não se interessa apenas pelo jornalismo e sim pela comunicação, de maneira mais ampla, onde há outras práticas de comunicação (publicidade, discurso político, discurso religioso, ou a propaganda militar, não importa qual discurso). E todo mundo se interessa pelo digital, porque temos a impressão que tudo está mudando em função do digital. Então são questionamentos que irradiam, não só em volta do paradigma jornalístico. Isso responde muito à preocupação profissional, porque os agentes estão vendo que as coisas mudam. Eles se perguntam e isso volta até a universidade e até os centros de pesquisa que incorporam esses questionamentos. 


\title{
Referências
}

CHARRON, Jean; DE BONVILLE, Jean. Nature et transformation du journalisme: théorie et recherches empiriques. Québec: Les Presses de l'Université Laval, 2004.

CHARRON, Jean; DE BONVILLE, Jean. Natureza e transformação do jornalismo. Florianópolis: Insular, 2016.

\section{It is not a journalistic crisis, it is a funding crisis: an interview with Jean Charron}

\begin{abstract}
In this interview, the researcher Jean Charron, from Laval University, Canada, argues that the contemporary journalistic paradigm is still the "journalism of communication", that emerged around the 1970s and 1980s. The model created by him and Jean de Bonville, in 2004, is described as a period of multiple supports, hyper-competitiveness, overabundance of information and emphasis on the phatic function of the discourse. To build this concept, the authors used Weber's ideal type method to reconstruct the history of journalism, since the $17^{\text {th }}$ century. Finally, the author argues that, nowadays, there is not a journalistic crisis, but there is funding crisis.
\end{abstract}

\section{Keywords}

Journalism. Journalism of communication. Jean Charron.

Recebido em 29/04/2018

Aceito em 18/05/2018 